\title{
Mapping the Achieved Values of Legal Reference Books onto the Digital Future
}

\author{
By Elizabeth Outler \\ Associate Director, Legal Information Center \\ University of Florida \\ elizout@gmail.com
}

This is an Accepted Manuscript of an article published by Taylor \& Francis in Legal Reference Services

Quarterly on 16 Sep. 2015, available at http://www.tandfonline.com/10.1080/0270319X.2015.1081006. 


\section{Abstract}

Web-based platforms for online reading and research create increasing accessibility of information but more challenging "findability." This article discusses concerns about losing the "values" of print-based research, as more libraries drop print subscriptions and reference materials and rely exclusively on electronic access. The visible organization of information, as well as its physical layout, make real contributions to the way we find answers and how we understand what we find. In the ongoing transition away from print resources, librarians have opportunities to carry forward the values of print into the digital future.

KEYWORDS: reference, books, print, legal reference, librarianship, bibliography, legal research, collection development, search engine

\section{Introduction}

We now live in the early part of an age for which the meaning of print culture is becoming as alien as the meaning of manuscript culture was to the eighteenth century. ... Far from wishing to belittle the Gutenberg mechanical culture, it seems to me that we must now work very hard to retain its achieved values. ${ }^{1}$

The death of the book has been happening for a long time. Perhaps only futurists thought such things 50 years ago, but it is striking today to realize that someone could have written in 1962 that print was becoming alien. Since that time, of course, many prognosticators, pundits, philosophers, and journalists, not to mention just about anyone else, have spoken of the impending death of the book. Here is another quote that seems like it could have appeared yesterday.

In the real world nowadays, that is to say, in the world of video transmissions, cellular phones, fax machines, computer networks, and in particular out in the humming digitalized precincts of avant-garde computer hackers, cyberpunks, and hyperspace freaks, you will often hear it said that the print medium is a doomed and outdated technology, a mere curiosity of bygone days destined soon to be consigned forever to those dusty unattended museums we now call libraries. Indeed, the very proliferation of books and other print-based media, so prevalent in this forest-harvesting, paper-wasting age, is held to be a sign of its feverish moribundity, the last futile gasp of a once vital form before it finally passes away forever, dead as God. ${ }^{2}$

Maybe that does sound a little too old to have been said yesterday, but surely one would not have guessed it to be 20 years old. Things happen faster, and slower, than perhaps we imagine they do. McLuhan and Coover thought they were describing very technologically advanced times, and of course they were. One wonders, however, what they might think if a time machine dropped them in 2015. Similarly, it is reasonable to wonder how this article will appear to a reader decades hence. The point is, how dead is the book? How dead will it be? Dusting off these old quotes is certainly not scientific, but it does seem to demonstrate that the book death process has 
been ongoing for some considerable time, and while its progress toward the end may be accelerating, it does appear to be quite a lengthy continuum. Therefore, if even now the book is only somewhat dead, perhaps this extended transition informs how we should treat it in the meantime.

For the great majority of researchers in every discipline, even some very sophisticated ones, the Internet is already the only platform for research. ${ }^{3}$ This article asks what will become of our traditional research tools, such as bibliographies, research guides, tables of contents, indexes, and digests. In the future of legal information, is there a place for these formerly essential research tools? It seems they may already be passé at a time in which they could be as necessary as ever. As more libraries decide it is time to rely almost entirely on electronic resources and divest their print collections, perhaps it is time to examine the role of the classic tools of legal reference and the lessons they hold for the future of law librarianship. These tools remain crucial features of the legal information landscape. Rather than mere relics of a biblio-focused legal information universe that made them essential because of the limitations of a print library, the special finding tools of legal research continue to retain remarkable relevance and usefulness in a field that grows ever more arcane in spite of its increasing accessibility. The emphasis on bibliography (for lack of a better umbrella term) as a core function of law librarianship should be revived if the profession wishes to remain equally relevant and useful.

One of the more dangerous pitfalls of our societal transition from the mechanical culture into the electronic one is that we are moving too fast to catch hold of and retain McLuhan's "achieved values." 4 The last few years have seen some big moves toward abandoning print resources from some noteworthy law libraries. ${ }^{5}$ These steps were taken partly in response to outside forces (e.g., the financial disaster, the ongoing economic recession, the resulting changes in the ways law firms do business, and the declining enrollments in law schools), but it seems that many law librarians today have come to the conclusion that formerly robust print resources are no longer worth the investment. ${ }^{6}$ Much of the support for the divesting of print subscriptions is the assumption that everything is or will be online. ${ }^{7}$ In some ways the command to cut budgets is welcome because it relieves the secret guilt over spending many thousands of dollars on books containing material that is duplicated in more than one very expensive electronic resource. This is made worse by the fact that most of the printed materials we buy these days end up covered with dust and remain free of fingerprints. There is no question that many collections of continuing print publications cannot be sustained even in the best-funded libraries. It is very difficult to continue paying for print subscriptions to reporters, statutes, legal encyclopedias, law reviews, and journals, the many titles that are often generally categorized as "treatises," especially those produced in a loose-leaf format, other titles such as American Law Reports and AmJur Trials, and all the print reference directories and indexes when all are available electronically. ${ }^{8}$ We need to be aware, however, that the exchange between what the database provides and what the print materials offered is not one-to-one: a gap remains that must be filled.

It therefore seems important to identify and preserve the essence of legal reference tools: the "achieved values" of print culture that McLuhan described. I focus particularly on reference 
works because it is this sort of book that seems most dispensable to many users and even librarians.

To assist in articulating the elusive "achieved values," metaphors are helpful. When starting out on a research question, the amount of information available can feel vast and complicated. One thinks of huge spaces, like a desert or an ocean or a mountain range, and dark meandering places like a swamp or an old forest. Words like wilderness and morass come to mind. The enormity of these physical environments is something we may be able to take in with our eyes, but our minds have difficulty quantifying the size or depth of what we behold. Once we begin moving within such spaces, it is possible to quickly become lost because of the difficulty of maintaining reference points for where we have been and where we are trying to go. Ad hoc strategies and solutions can work but often are not optimal. Hansel and Gretel had to try different methods, some of which failed to enable them to find their way home. ${ }^{9}$ To really feel confident about going there and back again, you need a map and a guide. We have had taxonomies of subject headings, indexes, digests, annotators, and citators to help us navigate the wilderness of printed legal information.

Meticulous bibliographic work was done by legal publishers and librarians to create the guides and maps. To keep up with the explosive development of information technology and the growing volume of case and statutory law, legal publishers have by necessity automated most, if not all, of this work. Librarians need to continue the careful bibliographic work, no matter how esoteric, and not abandon it as a casualty of the information revolution.

Previously labeled "bibliographer," current day librarians are "metadata specialists." Public services librarians do this in different ways than catalogers; nevertheless, what is important is that librarians today do not move away from this vision of librarianship. Law librarians are certainly becoming teachers and trainers and information consultants in their organizations, and that is an important role to maintain. But it is not enough to focus our energies on the interface. In this time of transition, it is crucial to retain a focus on information organization and metadata. There is rapid, ongoing digitization, and it may well be possible that all of our legal research tools will be available online in the near future; maintaining the meaningfulness and discoverability of these materials should now be our concern.

Electronic research tends to make us blind to the existence of anything else. In a 2003 article, Richard A. Danner illustrated concerns about electronic research edging out print sources by quoting Karl Llewellyn, ${ }^{10}$ who warned about the "threat of the available," which was described as "the almost inevitable tendency in any thinking, or in any study, first to turn to the most available material... [and] having once begun the study of the available, to lose all perspective and come shortly to mistake the merely available, the easily seen, for all there is to see." 11 Assuming Llewellyn was right about this tendency in 1931, how much more are researchers likely to behave this way when using Google, Westlaw, or Lexis? I argue that the best approach to addressing this gap is to fill it. We cannot fill it by pretending along with our users that there is a one-to-one exchange between the old sources and the new or that the new methods only improve upon the old. There are gaps and problems and unaddressed needs, and we should fill them the way librarians always have: by creating indexes, bibliographies, directories, and any 
other maps and guides that we and our users require. Bibliography, for lack of a better word, is the practice and province of librarianship, and counterintuitive as this may sound, there is no better time to revive it.

\section{The Achieved Values of Print Culture Organization of Information}

The most significant accomplishment of print in the realm of legal research may be the organization of legal information. Among the many celebrated legacies of the West Publishing Company is the taxonomy it developed for its digest system. Others have remarked upon the influence of the West digest system on the thinking of lawyers and possibly even on the development of the law itself in the United States. ${ }^{12}$ It is not necessary to go so far in arguing for its significance, however. Whether or not the West system created ${ }^{13}$ (or bounded) ${ }^{14}$ legal thoughts via its taxonomy, the strength and breadth of its system created a map of case law research that previously did not exist. ${ }^{15}$ The headnote and key number system of the West digest developed alongside its reporter system. As the mass of reported case law grew, it became increasingly difficult for lawyers to find what they needed. Apparently, in the late 19th century many lawyers experienced "information overload" in much the same way that we do today. ${ }^{16}$ Ironically, West's approach to publishing case law (i.e., comprehensively rather than selectively) was a major contributor to this problem; however, the key number system created the map that was necessary for coping with it. ${ }^{17}$ Without the possibility of full-text searching, the only means of finding judicial opinions containing holdings relevant to the researcher was the key number system. The only real alternative would have been constant reading of current awareness and maintaining one's own index of potentially useful decisions, a labor-intensive solution likely to be riddled with holes.

There are of course other innovative legal research tools. For example, in 1969 the Congressional Information Service (CIS) practically invented federal legislative history research. Before CIS began comprehensively indexing and abstracting federal legislative documents, it was quite difficult for a researcher to find and acquire the documents generated by Congress in the development of legislation and particularly in the case of failed legislation. Among the true boons of the CIS system was their creation of a classification system of access points. The entry in the CIS Index under "Statistical Data" is a striking example. The 2012 Index contains five pages of items listed under Statistical Data, demonstrating the enormity of statistical data reported by or to Congress in a year. If a researcher today, searching a full-text database, wanted to find law enforcement statistics in congressional documents, however, what query would he or she submit? Most, if not all, of the items under the heading "Statistical Data: Law Enforcement" do not contain any of those words in their titles and may not contain them at all. It would be difficult to develop good search terms for this inquiry. It is only via classification and indexing that such materials are grouped together, and only the index can give the researcher anything like confidence that he or she has retrieved a comprehensive result set.

The West Digest System and the CIS Indexes and Abstracts seem like relics to legal researchers today, particularly in print. The lawyer, the law student, and even the law librarian prefer to use a full-text electronic database to search and retrieve documents in what feels like one motion, 
without the intermediate step of consulting a separate index (or multiple indexes). An experienced and well-trained librarian knows that the digest is available in Westlaw, and the CIS Index terms are available in ProQuest Congressional. The difference now is that one has to know the index is there, what it is good for, and how to use it. Typically, only a librarian who has used (or been trained to use) the CIS Index to search for statistical data would know to seek appropriate index terms in the database. In the print world, one had no choice. The digest or the index was the only way to the information. Along the research journey these various featuresthe organization of information, the context clues and structure, along with the value-added features of the index - taught researchers some of the things they needed to know about the answer to the research question. The answer was not merely the document that was found at the end of the road. Documents always sit in relation to other documents, particularly in law. One of the key achievements of print legal research was that one was ever aware of this relationship because the structure was always visible. ${ }^{18}$ Researching in an online database environment encourages one to ignore it.

\section{Wayfinders and Guides}

An important feature of print legal research that continues to serve us in the electronic realm is the presence of wayfinders and guides. These are tools that are less concerned with constructing order out of the wilderness of legal documents but focus instead on illuminating the links between things. The most significant of these is the Shepard's Citations Service (and other subsequently developed citation services). Shepard's developed into much more than a system for confirming that a decision was "still good law." The tool made apparent the invisible links between cases, implicitly created by their citation of each other, and it eventually developed the links between case law and other sources as well, guiding the researcher along paths of information that otherwise might only be found after considerable toil.

Another truly remarkable wayfinder tool in legal research is the Annotated Statutes. This type of resource is so commonplace now that it seems heavy-handed to insist upon its specialness, but as with Shepard's, it is hard to imagine legal research without this Baedeker that guides one along the latent trails of links from this to that. The links are essentially brought into being by the act of looking for them, but they are nevertheless real and rather important. That is, the editors who put together the annotations need not (and probably cannot) envision the myriad scenarios that will drive researchers to the various uses of their product nor the impetus that will cause them to create links of meaning and application to individual situations. They lay the groundwork for that lawyering, however, by building the framework for it into the tool.

These links between documents that are inherent in the law and in lawyering, and which are built into the taxonomies and core wayfinding tools of legal research, should sound a little like something else we have grown accustomed to using. This is a hypertextual universe, much like the one made possible by Web-based tools. As mentioned earlier, these tools that were crafted to make sense of legal research in the print-based environment are quite present in Web-based databases now. The citation service and the annotated statutes have made particularly successful transitions into the electronic world, much more so than the taxonomies of subject organization. Arguably this is because these wayfinder tools are so well suited to the linking of the Web-based 
platform. An important consideration in judging the perceived success of this transition is whether we imagine that automated systems would find or create or illuminate the same links in the same way. Susan Nevelow Mart has conducted some studies trying to ascertain this. ${ }^{19}$ She concluded that human editing contributes to better results and therefore remains a crucial component of online research tools. ${ }^{20}$

There are some, like futurist Richard Susskind, who insist that search algorithms and other intelligent systems will be able to do for us what currently still requires human indexers. Susskind has written that "we are currently using just a tiny fraction of the search capability we will develop in due course." ${ }^{21}$ However, Susskind tells us that the future of search development will take more time than most users think.

"Optimum retrieval"... refer[s] to the quest for a search capability that is so impressive that users feel confident their system can immediately isolate, where this is meaningful, the single best document that is available for their purposes. This is not a document of whose existence the user is aware... but material that is, almost magically, unearthed and dispensed authoritatively as the most definitive and pertinent source available. ... It will take longer than ten years to achieve optimum retrieval but, within that period, I have little doubt we will see major advances. $^{22}$

Susskind goes on to describe the idealized vision of the future of search and data manipulation that has long been forecast: "Would it not be wonderful if we could ask a question, in ordinary language, and out would pop an answer, at an appropriate level of detail and with a suitable body of supporting arguments and evidence?"23 He states that such developments will be long in coming, at least two decades away, and even then would be at a crude stage of development. ${ }^{24}$ But his statement about how users regard the current ability of search engines in comparison to this future world is very apt:

Users should not be deceived by the impressive way in which a question inserted in a search engine in ordinary language may indeed deliver up some relevant documents. Often, this is the power of a successful fishing expedition and, at best, furnishes documents that, in some sense, contain an answer. It is a massive leap from this to a system that can answer questions on a wide range of issues in the manner of highly intelligent human beings. ${ }^{25}$

Bob Berring concluded that "the careful, methodical work of great bibliographers is a vocation being consigned to the past. It was tied to the three-dimensional object, and it solved the problems and challenges of the era of the book. Trusting an authoritative mind has given way to the use of a great search engine." ${ }^{26}$ As Susskind noted, even a great search engine is nothing compared to what we will see in the future. Therefore, on the one hand, Berring's statement of doom can be seen as too extreme; the traditional tools of research and reference cannot be dead yet. On the other, of course, he has not even envisioned the future tools that Susskind discusses, which are far beyond what our current tools are capable of. In that future world, perhaps our traditional tools are truly dead. But if the new tools are truly capable of what Susskind claims 
they will be able to do, then at that point we will know that we no longer need them. Does it matter whether these predictions are correct? Why does it matter whether humans remain involved in the production of these kinds of research tools? Answering this question returns us to the premise that there are values, or ways of thinking and understanding, that are so rooted in print culture that they must be translated. Machines may never be able to do that translation because they are completely free of the influence of the frameworks that the relationship with print has developed in the human brain.

\section{The Cognitive Metaphor of Print}

The metaphor about navigating physical space, previously referenced to discuss print tools constructed over the last century to work with legal information, feels apt for a reason. Recent research suggests that the human brain may perceive information, particularly printed information, as a kind of physical landscape. "The exact nature of such representations remains unclear, but some researchers think they are similar to the mental maps we create of terrainsuch as mountains and trails..." 27 If this is the case, we can see even more acutely how important the container for information can be. Brian O'Leary exhorted us to focus on the context, not the container. ${ }^{28}$ Yet research and experience shows that context is often provided by the container; they are one and the same. In other words, "[ $t]$ he medium is the message." 29

"In contrast, most digital devices interfere with intuitive navigation of a text and inhibit people from mapping the journey in their mind." ${ }^{30}$ Not only does the physical representation of text on screens make it very difficult to make landmarks for oneself to aid learning and memory, there are many features of electronic reading tools that distract attention, thereby interfering with retention. In addition, much of the utility of print documents arises out of their layout. For example, one of the features of print that continues to make it difficult for people to transition completely to paperless work is the ability to annotate documents - with arrows, or with sticky notes, we point to where information is on the page, or where we want it to go. It has been hard for electronic interfaces to provide this kind of utility. Further cause for concern is the aforementioned evidence that has surfaced that we think differently when reading and learning from screens - and not in a good way. ${ }^{31}$

Therefore it seems that one of the challenges we face is how to live in a digital information universe and somehow translate the maps and wayfinders that were developed in print so that they continue to work. This is quite a challenge for a number of reasons, but they tend to boil down to the same thing - i.e., that the salient features of Web-based information operate counter to that goal.

\section{Disintermediation (and Disaggregation) of Web Culture}

\section{Dominance of Search}

Full-text searching has become the dominant research method for very good reasons. It is powerful and convenient. It is straightforward and simple to use with little or no training. When a search algorithm is well designed, it gives the user a sense of control over the mass of information that seems to be reachable at the tips of one's fingers. Documents are available with an ease that was never before possible, using a method that was completely unavailable in the 
print-based world. While the search results appear to be the essence of aggregating and of making connections and building meaning, search algorithms actually disaggregate information. Choosing search as a research method is simply executing an automated retrieval of documents that match the given criteria. The only apparent connections between the retrieved documents are that they share some portion of the search criteria (depending on the commands entered). The documents may or may not share more meaningful connections, e.g., the connecting links described earlier that exist between cases when one cites another or when both cite the same authorities. A result set is only a list of hits, no more and no less, and even the available means for organizing them (relevance, type, date, etc.) yield no additional hints about the relationships between them or the overall meaning, if any, to be gleaned from the pile.

Interestingly, this stack of hits contributes to the level of satisfaction users tend to feel when executing searches. If one or more good documents are quickly identified, we think the search was successful. In reality, however, it is impossible for the researcher to tell merely from this stack, whether there were other good (or better) documents findable in the available universe of possible results. Links to related documents may be available, but as noted, it can be difficult to see the nature and significance of the relationship before clicking through. Time spent following such leads, many of which provide no additional meaning, teaches the user that such clicking can be no better than a fishing expedition. Ironically, the search query the user started with was precisely such a fishing expedition, but combined with its ease and convenience, its results were satisfying enough to train the user to believe in its superiority as a research method.

Laws, however, cannot usually be separated into disaggregated, standalone documents. If one needs to find the governing statute for a specific issue, finding a statute that matches the search query, without looking any further, is likely to come up short of the entire legal picture. It is likely to miss a different section that defines exceptions to the rule, or a judicial decision that defines elements that must be met before the rule applies. The traditional taxonomies and wayfinders of print-based legal research, however, would show the additional documents to the user almost involuntarily. With Web-based search results, we actually have to work harder to make those connections, yet we are far less inclined to seek them.

In addition to disaggregating information sources, online searching causes disintermediation. Although the ability to scan across the universe of documents and define one's own criteria for retrieval enables the researcher to break free from the myopia and bias of the indexer, the researcher brings his own biases to the search. A researcher is often much less prepared to think broadly and examine his prejudices than the indexer. Therefore, even though he is empowered to build his own terms for retrieval, he is still unable to craft the best search criteria because of his inability to fully appreciate his surroundings. As Donald Rumsfeld famously said, there are known unknowns, and there are unknown unknowns. ${ }^{32}$ Without help, the researcher cannot be aware of the unknown unknowns. One of the most valuable things that classification and organization tools provide is an inventory of the unknowns so that the researcher is much less likely to be completely unaware of what he does not know. This is lost when we abandon visible classification systems and indexes entirely. 
An example may be necessary to fully illustrate how the unknowns problem still presents itself to researchers attempting to adapt to online-only resources. I know of two law professors who have struggled with the loss of print finding tools because search does not deliver the answers they need. One wants to be able, at the end of a year, to flip through the Internal Revenue Bulletins to see what Treasury Decisions were issued in her subject area that she might have missed or failed to appreciate when they were issued. There is no way to craft a search that will deliver that to her. There are online files available that replicate the print, and she can skim through those, but it is cumbersome and time-consuming, to click and download each of the 52 files. There is no electronic cumulative table of contents for the year, and it was significantly faster and easier for her to flip through the print bulletins. A similar story involves a professor who complained about the cancellation of the Federal Rules Decisions reporter in print. Like the tax professor, he used the table of contents for the volumes issued in a particular year to see the decisions that were printed there. It was difficult to craft a successful search that would give him exactly that list. "I suppose I can survive in the new world," he said. "I can search in FRDRULES for the rule amendments, as long as I know what to search for."

Online searching works optimally when researchers know something about what they want to find. As these two professors illustrate, however, this is not always the case. Sometimes researchers want to see the entirety of the information available instead of limiting the available results based upon a preconceived idea. The structure and guidance of the print finding tools allows for this type of research. Furthermore, although these researchers were intentionally seeking unknown unknowns, the typical online researcher is not even aware of the unknowns their searches are missing.

\section{Loss of Context and Meaning Provided by Visible Information Organization Schemes}

There is an irony about the perceived disintermediation in Web-based search engines. The intermediaries are still there, but they have become invisible to the user. The classification systems, indexes, and the like are hidden inside the "black box" algorithm. We usually do not know, or even want to know, how it works. What is lost when the familiar structure and reference points for legal information finding are no longer visible? There is a degree to which the structure itself empowers you in a way that sifting through chaos cannot. Awareness of the structure creates efficiencies. It also enables a certain amount of creativity and insight. Recently I was kidded by a colleague about a habit I apparently have of enumerating points in emails. "I am glad you numbered that list," he said. "What if I had read them in the wrong order?" A light went on for me. "I do it so that you can read them in the wrong order," I responded. Without the ordering I had provided, my reader might never have thought consciously about how the information should flow; even with the enumeration, he still might not, but making it visible inspires such thinking. It has been argued that the organization of legal information prevents one from truly creative thinking: It tells us what to think, thus closing off possibilities that are outside the paradigm. ${ }^{33}$ But without the visible structure, what is there to inspire critical thinking about the organization of ideas (and thereby about the ideas themselves)?

The development of writing is one example of how the imposition of a structure on the expression of ideas made possible vast expansions in communicating and understanding ideas. 
Maryanne Wolf, a researcher of reading and language development, describes how the invention of writing made possible the development of ideas and the acceleration of culture that could not have happened without it.

Try to imagine a situation in which the educated members of an oral culture had to depend entirely on personal memorization and meta-cognitive strategies to preserve their collective knowledge. Such strategies, however impressive, came with a cost. Sometimes subtly, sometimes blatantly, dependence on rhythm, memory, formulas, and strategy constrained what could be said, remembered, and created.

The alphabet and other systems did away with most of those constraints, thereby enlarging the boundaries of what could be thought and written by more people. ${ }^{34}$

A similar imposition of structure and associated limits on thinking is the development of the paradigm and its role in the scientific enterprise. Thomas Kuhn suggested that the paradigm both inhibits and allows for scientific thought and progress. ${ }^{35}$ Revolutions in scientific understanding are made possible by the development of the paradigm and especially by its limits. Without the framework of the paradigm, scientists would have to spend all their time developing fundamentals and describing any and all phenomena they find, and little progress would be possible. ${ }^{36}$ The unifying theory and structure provided by the paradigm resolves unknowns and frees the researcher to focus on particular problems. ${ }^{37}$

Normal science, the activity in which most scientists inevitably spend almost all their time, is predicated on the assumption that the scientific community knows what the world is like. Much of the success of the enterprise derives from the community's willingness to defend that assumption, if necessary at considerable cost. Normal science, for example, often suppresses fundamental novelties because they are necessarily subversive of its basic commitments. Nevertheless... the very nature of normal research ensures that novelty shall not be suppressed for very long. ${ }^{38}$

As Kuhn noted, this is what Francis Bacon meant when he said "Truth emerges more readily from error than from confusion." " 39 The paradigm is limiting; there is no denying that. It is also the driver for revolutionary changes in thought.

It is too early to name this 21 st-century transformation from print culture to Web culture. The Web-based tools we are currently immersed in are unlikely to be the stable technology that eventually rises to prominence. The current hand-wringing about the loss of the strengths of the print culture in our rapid transition to the visual/digital culture is similar to Socrates' complaining over the loss of the oral culture. Socrates was not wrong, but he did not understand or appreciate how big the payoff was going to be. We should keep in mind that we might be in the early stages of an equally significant culture shift to something we cannot even imagine. It is tortuous to be the ones in the midst of the transition, responsible for preserving the links to the old ways, and to be casting about for new ways. We must keep in mind that we are in the midst of a monumental transition. While it seems that everything is changing, many of the old tools 
still work. The legal bibliographic structure still underlies all of our Web-based databases. The danger we face is dancing faster than the music: discarding and abandoning paper resources before they have outlived their value. It is comforting (and instructive) to remember that people still wrote by hand after the invention of the printing press. As William Powers noted, "for any literate person, writing was still absolutely necessary. The point is that it became even more essential after print's arrival, and played a major role in the evolution and culture of that technology." 40

\section{Disproportionate Emphasis on Finding, Rather Than Understanding}

"When reading on screens, individuals seem less inclined to engage in what psychologists call meta-cognitive learning regulation—setting specific goals, rereading difficult sections and checking how much one has understood along the way." ${ }^{41}$ In their 2008 article, Marci Hoffman and Katherine Topulos wrote about this concern in the context of international and comparative legal research. ${ }^{42}$ Their article focuses mainly on the difficulties of foreign, comparative, and international law (FCIL) research caused by gaps in available materials, both in print and online. They point out that

access to more content and better technology may make research even more difficult. The use of Google and Google-like interfaces is making it more difficult to teach students and practitioners (and even some faculty) that they need to do more than a mere keyword search. As noted by Richard Danner, "Legal research requires complex finding tools, as well as the means to evaluate how current the sources are and to measure the continued validity of the sources." 43

The typical effect of Web-based searching, however, is to create uncritical and impatient researchers. Hoffman and Topulos point out that in the highly specialized and often difficult realm of FCIL research, such impatience and inattention often means the research fails.

Researchers unfamiliar with these sources often give up on a database if it is not available in English or is not structured to search in the same manner as LexisNexis, Westlaw, or Google. This is compounded by the fact that they may not understand how law is organized in another country or by an international body and therefore search for the wrong kinds of materials or use the wrong terminology. ${ }^{44}$

Of course, as noted earlier, for many questions in domestic law, the research does not fail. The search does return results, at least some of which seem satisfactory, and the same impatient researcher sees no reason to go further.

Even if researchers do not need the expertise of a scholar to index and abstract the best or most relevant sources and organize them by subject anymore, perhaps they still appreciate the convenience of a single source for certain types of facts. Almanacs, books of quotations, statistical compilations, and directories all retain significant usefulness in the face of information overload. As the amount and variety of information available online expands, the need for convenient compilations of information (combined with a named source) becomes more compelling. However, as noted, researchers and librarians have become far less reliant on such 
sources and, it seems, possibly less aware of them as a consequence. When we saw the Congressional Yellow Book on the shelf, we remembered its utility; we may forget about the Leadership Directories Online as a resource because we do not see it. A New Yorker cartoon illustrates the way digital resources hide from our awareness: Two men are sitting at the beach, and one of them says, "I got tired of Moby Dick taunting me from my bookshelf, so I put it on my Kindle and haven't thought of it since." 45 The reliance on search as a solution to all research problems becomes so pervasive that it defines other sources out of existence.

\section{Conclusion}

To close, I would like to dust off another old quote, this one a little more truly prescient:

It is not too great or unwarranted a step to assume further that the law, or the learning and exposition of any group, is constantly being modified by the means of gaining access to it. An understanding of this phenomenon ought to lead us to deeper study of the implications of such things as computerized data banks for legal or governmental documents, and the role of Government in providing access to that information. ... At the same time, an understanding of our own and our professional group's relationship to our bibliographic tools may provide some means of measuring both our progress and our shortcomings. ${ }^{46}$

What seems important now is to get some clarity about what librarianship and libraries can and should provide in an increasingly digital world. This conversation has been going on in the profession for some years now, as the predictions and discussions of the demise of the book have grown. In taking up McLuhan's suggestion to focus on the achieved values of print culture and seek those that should be preserved, we can use those values to identify the essential contributions of librarianship to the information society. It is something other than book storage and cataloging and more than a space or an "information commons." It is not merely services. I argue that librarians are and should be especially devoted to serving and furthering the world made possible by books and bibliographic tools. We may be "information specialists," but that is only part of what we are. We should not be fooled into believing that the portents of the death of the book must necessarily lead us to the death of bibliography. Many of us have become apologists for the book, when it seems to me that the times now call for unapologetic advocacy of the values of print. Why not be full-throated champions of books, and specifically reference books - the purposefully designed and highly functional special tools that have no substitute and which only we seem to remember? The need for the skills of professional information stewards has not diminished in the Web-based information culture; it has increased as information becomes more accessible but less findable. This is especially true in law librarianship because legal research is particularly benefitted by certain kinds of bibliographic aids. The law is made up of many individual documents and therefore quite susceptible to the disaggregation of fulltext electronic searching. As a profession, we have been eager to innovate and to avoid appearing stuck in the old ways. Perhaps we have been too eager to sacrifice those ways too quickly. Until we have an adequate replacement, a truly new way that serves all our users' needs, the old ways are still necessary. If we jettison our ability to continue researching in the ways that work, we do a disservice to ourselves, to our constituencies, and to society. 
If we are moving from being collectors to being service providers, then let us provide library services. If we cannot preserve print reference works, we can make them ourselves. The faculty member who wants to continue scraping the Federal Rules Decisions for current awareness and for serendipity has a legitimate need, and assuming Westlaw is not likely to provide electronically the finding tool he formerly used in print, then his librarians could reproduce it. Likewise for the tax professor: Her librarian could assemble the cumulative table of contents for her (or train her research assistant or other support staff to do it). These are simple requests, on one end of a spectrum of complexity that librarian expertise and energy surely can accommodate. As digitized material becomes invisible because our screens provide no context and few pointers, bibliographies and other finding tools become exceedingly important to researchers. Making search better only goes so far; making visible the indexing and classification systems that lie beneath the surface may change the way that users experience search tools and the results they get. I do not know how to make these tools visible, but I have reached the conclusion that that is what is missing in the transition away from print and it is how we bring forward the values of print into the digital future. In 2000, Bob Berring called out to the legal profession that it must

"seize control of its own information destiny. The time is now, the stakes are enormous." 47 In 15 years, nothing has changed, and everything has changed. We still have time in the legal library profession to make our marks and shape our information destiny.

We can rediscover the exercise of recommending books. ${ }^{48} \mathrm{We}$ could be researching narrow yet important topics in order to provide guidance to our local users and the global research community. We should be documenting the best ways of using special tools and finding special information. Of course, we can contribute directly to legal scholarship as well. As Lyonette Louis-Jacques has exhorted, let us write about "the unpopular, the weird, the old, the outside, the unexpected, the obscurities buried in ancient tomes, and the unsafe topics that do not make headline news." 49 Librarians need not be policy scholars, but we can do a great deal to advance our profession and the legal profession as a whole, if we choose to be. The central theme of this article, however, is that whatever form our activities take, as teachers, authors, bibliographers, or research assistants, to remain librarians we need only be treasure hunters and map makers, as librarians have always been. We are not in the business of being better searchers but rather better finders. We can find information because we have organized it. Retaining the achieved values of print culture means making visible our information architecture that allows Web culture to flourish. That is what librarianship should focus on today. Providing that context empowers our users to find what they really want and to actually understand it when they do. Let us reestablish ourselves as expert guides, pointing out pathways for those who would otherwise stumble and flounder in the wilderness of legal information or clearing new trails for those seeking adventures there.

\section{Acknowledgments}

The author wishes to thank the participants at the Fifth Annual Boulder Conference on Legal Education: Teaching \& Scholarship held at the University of Washington School of Law, Seattle, Washington, on July 11-13, 2013, for their helpful review and commentary. 
${ }^{1}$ Marshal Mcluhan, The Gutenberg Galaxy: The Making OF Typographic Man 165 (University of Toronto Press, 1962).

${ }^{2}$ Robert Coover, The End of Books, N.Y. Times Book Rev., June 21, 1992, available at https://perma.cc/259M-LELU.

3 "The days of conducting legal research in books are over." Ellie Margolis \& Kristen E. Murray, Say Goodbye to the Books: Information Literacy as the New Legal Research Paradigm, $38 \mathrm{U}$. DAYTON L. REV. 117 (2012).

${ }^{4}$ See MCLuHan, supra n. 1.

${ }^{5}$ For example, in 2010 the Harvard Law School Library ceased collecting print reporters for anything other than the United States Supreme Court. The collection development policy also notes that for legal encyclopedias and most other secondary legal materials, the Law Library would not collect in print and rely instead on Lexis, Westlaw, HeinOnline, or other "stable, digital source." Harvard Law School Library Collection Development Policy, Feb. 17, 2010, available at http://web.archive.org/web/20111104193706/http://www.law.harvard.edu/library/about/collectio ns/collection_development_policy.pdf.

${ }^{6}$ See Nancy McCormack, Cancellation of Print Primary Sources in Canadian Academic Law Libraries, 104 LAW LIBR. J. 263 (2012).

${ }^{7}$ This remains a fallacy for the majority of the collection. Jerry Dupont of the Law Library Microform Consortium estimates that about $15 \%$ of law library collections are currently available electronically in some way (including Lexis and Westlaw). Hollee Schwartz Temple, Are Digitization and Budget Cuts Compromising History?, ABA Journal (May 1, 2013), available at https://perma.cc/N7ZL-F8DJ.

${ }^{8}$ See, e.g., Yale Law School Lillian Goldman Law Library, Collection Development Policy, Reference Sources, available at https://perma.cc/UM7V-ENEG (last accessed May 1, 2015).

${ }^{9}$ First the children marked their path as they went with pebbles, and this was successful. The second time they were prevented from collecting pebbles for this purpose, so they tried breadcrumbs. This tactic failed when birds ate the breadcrumbs before the children were able to attempt their return. Jacob \& Wilhelm Grimm, Hansel and Gretel, available at https://perma.cc/SN48-CD7S (last accessed May 1, 2015).

${ }^{10}$ Richard A. Danner, Contemporary and Future Directions in American Legal Research: Responding to the Threat of the Available, 31 INT'L J. LEGAL INFO. 179, 182 (2003).

${ }^{11}$ Karl N. Llewellyn, Legal Tradition and Social Science Method-A Realist's Critique, in ESSAYS ON RESEARCH IN THE SOCIAL SCIENCES 89, 95-96 (1931), reprinted in Karl N. Llewellyn, JURISPRUDENCE: REALISM IN THEORY AND PRACTICE 77, 82 (University of Chicago Press, 1962). 
${ }^{12}$ See, e.g., Robert C. Berring, Legal Research and Legal Concepts: Where Form Molds Substance, 75 CAL. L. REV. 15, 25 (1987) [hereinafter Berring, Legal Concepts]; F. Allan Hanson, From Key Numbers to Key Words: How Automation Has Transformed the Law, 94 LAW LIBR. J. 563, 568 (2002).

${ }^{13}$ Berring, Legal Concepts, supra n. 11, at 25.

${ }^{14}$ Richard Delgado \& Jean Stefancic, Why Do We Tell the Same Stories?: Law Reform, Critical Librarianship, and the Triple Helix Dilemma, 42 STANFORD L. REV. 207, 216-220 (1989).

${ }^{15}$ Thomas J. Young, Jr., A Look at American Law Reporting in the 19th Century, 68 LAW LIBR. J. 294, 302-306 (1975).

${ }^{16}$ See Thomas A. Woxland, "Forever Associated with the Practice of Law": The Early Years of the West Publishing Company, 5 Legal ReFerenCE SERVs. Q. 115, 117 (1985).

${ }^{17} I d$. at 120.

${ }^{18}$ Brian O'Leary, a publishing consultant and writer on the evolution of media and publishing, has argued that the way we think about print culture versus Web culture has been unduly focused on the container. He has pointed out that in the evolving Web culture, "We are no longer selling content, or at least not content alone. To support discovery and utility in digital environments, we need to compete on context. ... To compete digitally, we must start with context and preserve its connection to content so that both discovery and utility are enhanced." Brian O'Leary, Context, Not Container, in BooK: A Futurist's MANIFESTO 7-8 (Hugh McGuire \& Brian O'Leary, eds., O'Reilly Media, 2012). His point is about competition and success in the e-book industry, but it gives insight and ideas for addressing the challenges facing librarians.

${ }^{19}$ Susan Nevelow Mart, The Case for Curation: The Relevance of Digest and Citator Results in Westlaw and Lexis, 32 Legal RefERENCE SERVs. Q. 13 (2013) [hereinafter Mart, The Case for Curation]; Susan Nevelow Mart, The Relevance of Results Generated by Human Indexing and Computer Algorithms: A Study of West's Headnotes and Key Numbers and LexisNexis's Headnotes and Topics, 102 LAW LIBR. J. 221 (2010) [hereinafter Mart, The Relevance of Results].

${ }^{20}$ Mart, The Case for Curation, supra n. 18, at 43; Mart, The Relevance of Results, supra $\mathrm{n} .18$, at 241 .

${ }^{21}$ Richard Susskind, The END OF LAWYers? Rethinking tHe NATURE OF LEGAL SERVICES 66 (Oxford University Press, rev. ed., 2010).

${ }^{22} I d$. at 68 .

${ }^{23} I d$. at 69 .

${ }^{24} I d$.

${ }^{25} \mathrm{Id}$. 
${ }^{26}$ Robert C. Berring, The End of Scholarly Bibliography: Reconceptualizing Law Librarianship, 104 LAW LiBR. J. 69, 76 (2012).

${ }^{27}$ Ferris Jabr, Why the Brain Prefers Paper, 309 SCIENTIFIC AMERICAN 48 (2013).

${ }^{28}$ O’Leary, supra $\mathrm{n} .18$.

${ }^{29}$ Marshall McLuhan, Understanding Media: The Extensions of Man 23 (McGraw-Hill, 1964).

${ }^{30} \mathrm{Jabr}$, supra $\mathrm{n} .27$, at 51.

${ }^{31} I d$. at 48 .

${ }^{32}$ U.S. Department of Defense News Briefing, Feb. 12, 2002, available at https://perma.cc/8TAL-KV8R.

${ }^{33}$ See, e.g., Delgado \& Stefancic, supra n. 14.

${ }^{34}$ Maryanne Wolf, Proust and the SQuid: The Story and Science of the Reading BRAIN 65 (HarperCollins, 2007).

${ }^{35}$ Thomas S. Kuhn, The Structure of Scientific Revolutions (University of Chicago Press, 3rd ed., 1996).

36 "In the absence of a paradigm or some candidate for paradigm, all of the facts that could possibly pertain to the development of a given science are likely to seem equally relevant." $I d$. at 17.

${ }^{37} I d$. at $19-20$.

${ }^{38} I d$. at 5 .

${ }^{39} I d$. at 18 .

${ }^{40}$ William Powers, Hamlet's Blackberry: Why Paper Is Eternal 26 (2006), available at https://perma.cc/DME3-AW69.

${ }^{41} \mathrm{Jabr}$, supra $\mathrm{n} .27$, at 52.

${ }^{42}$ Marci Hoffman \& Katherine Topulos, Tyranny of the Available: Under-Represented Topics, Approaches, and Viewpoints, 35 SYRACUSE J. INT'L L. \& COM. 175 (2008).

${ }^{43} I d$. at 196.

${ }^{44} I d$. at 197.

${ }^{45}$ Cartoon by William Hefeli, New Yorker, Sept. 3, 2012, at 51.

${ }^{46}$ Young, supra n. 15, at 306. 
${ }^{47}$ Robert C. Berring, Legal Research and the World of Thinkable Thoughts, 2 J. APP. PRAC. \& PROCESS 305, 318 (2000).

${ }^{48}$ Linda S. Maslow, The Enduring Value of Books Related to the Law: A Librarian's Perspective, 113 Mich. L. REV. 761 (2015).

${ }^{49}$ Lyonette Louis-Jacques, Gaps in International Legal Literature, 1 CHI. J. INT'L L. 101, 108 (2000). 